\title{
EL COMPENDIO APOLOGÉTICO DE BALBUENA: LA INSERCIÓN POLÉMICA DEL POETA EN EL EDIFICIO CIVIL
}

El propósito de este trabajo es el estudio del Compendio apologético en alabanza de la poesía de Bernardo de Balbuena, y la polémica sobre su posible consideración como testigo de la conciencia y de la afirmación criollas a comienzos del siglo XVII. Para ello será necesario insertar la obra dentro de su contexto de producción, lo que implica abarcar las poéticas y alabanzas de la poesía escritas en castellano en fechas cercanas a la de la redacción del Compendio. Como se verá, la nota de civilidad de que se dota a la poesía y al oficio poético en esta obra es característica común a un grupo abundante de textos poético-doctrinales de la época, a uno y otro lado del Atlántico, aunque con Balbuena esta seña alcanza una peculiaridad propia. Este carácter civil de su defensa poética, a su vez, será el punto de partida para el estudio de la inclusión de Balbuena en la estructura letrada de poder y para la refutación de su pretendido criollismo de naturaleza escisionista.

El Compendio apologético puede catalogarse como poética en el sentido amplio de la palabra, por cuanto trata, entre otras cosas, del ser y esencia de lo poético, aunque consista en una alabanza de la poesía más que en una poética propiamente dicha². La idea cen-

${ }^{1}$ Cito por la edición de Luis Adolfo Domínguez, Porrúa, México, 1971.

2 Cf. E. Curtius, Literatura europea y edad media latina, trads. M. Frenk Alatorre y A. Alatorre, F.C.E., Madrid, 1981, pp. 760-775, donde se aborda el estudio del tópico de la alabanza de la poesía. Porqueras Mayo, en 1986, realiza un estudio de los textos de alabanza castellanos (Alfonso de Valdés, Gaspar de Aguilar y Fernando L. de Vera y Mendoza). Lope de Vega, en el discurso inicial de sus Rimas de 1609 (ed. Felipe B. Pedraza Jiménez, Universidad de Castilla La Mancha, Ciudad Real, 1993) y en el discurso final de la misma edición dedicado a Arguijo también participa de la misma corriente de ideas. El editor de las Rimas señala el Dell'arte poetica de Tasso (1587), el Syntaxeon artis mirabilis, de Pedro Gregorio (1583), y la Polyantea de Lyon (1600), como textos que sirven de inspiración a Lope. Para aquellas poéticas castellanas más o menos contemporáneas a 
tral que estructura la obra es la de la recuperación de la elocuencia dentro de un contexto político, urbano y civil ${ }^{3}$. El hombre, dentro de este sistema, se caracteriza por su capacidad elocutiva y por su ser social. En la Italia republicana de la segunda mitad del siglo Xv era donde mejor podía desarrollarse el renacer del ideal retórico latino de un vir bonus peritus dicendi que fuera además rector de la sociedad, de quien pudieran depender de modo efectivo, no sólo utópico como en los países de sistema monárquico, las riendas del gobierno. Junto a este renacer político de la capacidad elocutiva cabe situar el nuevo prestigio que alcanza la poesía como arte supremo de la palabra. No se trata de una poesía simplemente bella o adornada, sino de una que pronto, desde finales del siglo $\mathrm{XV}$ y por los esfuerzos que los humanistas han de hacer para prestigiarla frente a los ataques de los escolásticos, se identifica como ciencia portadora de verdad y de virtud. Junto a ella compite en ocasiones la historia, dando lugar al desdoblamiento de los conceptos de poesía virtuosa e historia verídica y moralizante que en ocasiones se cruzan ${ }^{4}$. Dentro del clima de saturación política del

la de Balbuena, véase Marcelino Menéndez y Pelayo, Historia de las ideas estéticas en España, CSIC, Madrid, 1940, caps. 9 y 10; KARL Kohut, Las teorías españolas en España y Portugal durante los siglos xv y xvi, CSIC, Madrid, 1973; y SANFord SHEPARD, El Pinciano y las teorías literarias del Siglo de Oro, Gredos, Madrid, 1962. Hay que citar junto a ellos, para el estudio de las ideas retórico-poéticas, a LUISA LóPEz GRIGERA, La retórica en la España del Siglo de Oro, Universidad, Salamanca, 1994, a modo de recopilación de sus estudios precedentes sobre el aspecto preceptivo de la retórica y su aspecto práctico, y Antonio García Berrio, Formación de la teoría literaria moderna, Filología Murcia, Málaga, 1980, donde se estudia en especial el paso de Vives a Antonio Llull y a Sánchez de las Brozas, por lo que toca a la preceptiva retórica, así como el desarrollo de la poética horaciana y del ingenium en el siglo xvi español. Para América, cabe citar a Antonio Cornejo Polar (ed.), Discurso en loor de la poesía, Universidad Nacional Mayor de San Marcos, Lima, 1964 y Mabel Moraña, "Formación del pensamiento crítico-literario en Hispanoamérica: época colonial”, RCLL, 1990, núms. 31/32, 255-265 y "Apologías y defensas: discursos de la marginalidad en el barroco hispanoamericano", en Relecturas del barroco de Indias, ed. Mabel Moraña, Eds. del Norte, Hanover, 1994, pp. 31-58.

${ }^{3}$ Entre los mejores estudios pueden citarse los de Hans Baron, Humanistic and political literature in Florence and Venice at the beginning of the Quattrocento, Harvard University, Cambridge, MA, 1955 y "Leonardo Bruni, «Professional Rhetorician» or «Civic Humanist»", Past and Present, 36 (1967), 21-37; Ronald G. WITT, "Florentine politics and the ruling class, 1382-1407", Journal of Medieval and Renaissance Studies, 6 (1976), 246-267 y B. G. KHOL \& R. G. WITT (eds.), The earthly Republic. Italian humanists on government and society, University of Pennsylvania Press, Philadelphia, 1991.

${ }^{4}$ Uno de los momentos culminantes de la confrontación de ambas ideas lo 
momento, y probablemente por medio del desarrollo de géneros como el regimen principum, se pasa de la consideración política de la poesía a la consideración política del poeta; es decir, a lo que ayudaba a la identificación de poesía con verdad y sabiduría y el encomio de la administración política de los sabios en la Política de Aristóteles y en la República y Las Leyes de Platón. En este proceso, cuyas etapas son algo más complicadas que el simple boceto trazado hasta ahora, se transparenta una sociedad jerarquizada e idealizada. El neoplatonismo, cuyos textos ya desde el siglo xv elaboraron una filosofía de estetización del orden, colaboró a la conjugación de los sistemas político y poético a través de obras como los Diálogos de amor de León Hebreo, el De institutione rei publicae de Francesco Patrizi, Los Asolanos de Bembo, El Cortesano de Castiglione o los Diez diálogos sobre la historia, de Sperone Speroni. Este platonismo-pitagorismo señalaba como un todo bello y armónico el conjunto del universo, a cuya imagen se reproducía el orden de la sociedad, de la familia o del mismo individuo. Así, el orden de lo humano copia el orden celeste y el orden divino, repitiendo una jerarquía organizadora en cuya base están las ideas de la participación filosófica, desde un punto de vista ontológico, y de la imitatio, desde uno estético.

Si bien la idea de la recuperación y exaltación de la elocuencia dentro de un orden civil adquiere un significado elitista o escapista en otras poéticas contemporáneas a la de Balbuena, en las que se concibe lo poético como perteneciente a la res publica litterarum, en el caso de éste la civilidad se carga de sentido, pues desde México está asistiendo a la creación de un cuerpo social y urbano casi de la nada que necesita definir su orden y jerarquía ${ }^{5}$. También en este sentido el género del elogio de ciudades en el que se incluye su poema Grandeza mexicana recupera el viejo sentido de los poemas épico-fundacionales ${ }^{6}$. Si la Eneida de Virgilio logra sentido dentro del ideal imperialista romano de la época de

supone la polémica quinientista sobre la épica. El trasfondo de las discusiones sobre materia remota y materia propinqua ha de insertarse en la concepción del género histórico-épico como modelo literario emparentado con la idea de verdad y englobado en el contexto de una república de las letras o de la ciudad letrada.

${ }^{5}$ Este cuerpo civil puede ser definido con Ángel RAma (La ciudad letrada, Eds. del Norte, Hanover, 1984) de acuerdo con la noción de ciudad letrada, que en América no es una república literaria desvinculada del contexto urbano y político.

${ }^{6}$ Véase MARio Rodríguez Fernández, "El tópico de la alabanza en la poesía barroca americana”, Revista Trimestral de Ciencias, Letras y Artes, 393 (1961), 202-225. 
Augusto, el poema de Balbuena en elogio de la ciudad de México ha de verse como el fundamento poético-civil de quienes están instaurando un nuevo orden en América. La idea aséptica en apariencia de la civilidad de la poesía se convierte con Balbuena en motor rector de una sociedad de nueva planta.

Quizá no sea casualidad que, del mismo modo que en la evolución del latín vulgar a las lenguas romances se observan fenómenos de evolución fonética o de preferencia semántica comunes a las áreas más alejadas del foco cultural romano, sean aquellas zonas más distantes del centro político español de los siglos XVI-XVII las que pretendan dar a la idea de la capacidad política del poeta un sentido verdaderamente efectivo. Entre 1550 y 1560 un grupo de estudiantes y profesores españoles de Lovaina se habían pronunciado a favor de estas teorías estético-políticas de ascendencia paduano-veneciana con el propósito de influir de modo directo (desde el consejo) en la conducción y organización del edificio político imperial ${ }^{7}$. A ello les movió, probablemente, su lejanía de la Península, donde se creyeron a salvo de ataques inquisitoriales. Del mismo modo Balbuena, en la lejanía de América, recupera las nociones de los libros de Patrizi para defender una mayoría de edad política de los españoles americanos que probablemente a más de uno sonara molesta. Si bien en ningún caso podemos hablar de ideas independentistas, sí existe un abierto reclamo de poder en ambos contextos.

Dejando a un lado las etiquetas de precriollismo o prenacionalismo, de todo punto anacrónicas, estamos tentados a ver en la voz poética de Balbuena la insurgencia, cuando menos, de una conciencia de grupo. Quizá, como en tantas otras esferas de los

7 Por lo que toca a la reflexión hispana humanística son sintomáticos los libros De rege regisque institutione, de Sebastián Fox Morcillo (1554), y su De historiae institutione dialogus (1557), que se han de unir a sus reflexiones sobre la filosofía platónica y aristotélica y a De imitatione seu de formandi stili ratione (1554), donde se ve clara la relación entre reflexión estética y política. Del mismo modo, Furió Ceriol publicó en 1559 Del Concejo y consejeros del príncipe, al que se une Bononia seu de libris in vernaculam linguam vertendis, publicado algunos años antes y en donde discute la posibilidad de traducir a las lenguas vernáculas las Sagradas Escrituras. En la misma línea, para Italia, Francesco Robortello escribió en 1548 In librum Aristotelis de arte poetica explicationes y Paraphrasis in librum Horatii, qui vulgo de arte poetica ad Pisones inscribitur, del mismo modo que años después escribiría De historica facultate. Se prueba, en el ánimo de estos humanistas, que la reflexión política nace de la estética y que su humanismo se emparienta de modo definitivo con el carácter civil del originario humanismo florentino de Leonardo Bruni. 
conflictos de poder, el discurso estético oculte reivindicaciones de otro calibre, que sólo en lo inocuo del frío esteticismo encontraron salida a su marginalidad. Moraña ${ }^{8}$, de modo cauteloso, habla de este fermento de actitudes diferenciadoras, aunque tiende a centrarse en figuras del último tercio del siglo XVII. Buxó ${ }^{9}$ niega que quepa ver en Balbuena germen alguno de actitudes precriollistas y centra acertadamente la ideología del obispo de Jamaica y Puerto Rico en el interés, ya a nivel nacional, ya a nivel personal. Sabat de Rivers ${ }^{10}$ ve en nuestro autor constantes oposiciones y críticas a la metrópoli, y hace de él un defensor del indio y creador de una conciencia nacional mexicana y americana ${ }^{11 .}$

\section{EL “COMPENDIO” Y SU RAZÓN DE SER RETÓRICA}

El Compendio o alabanza de la poesía de Balbuena se escribe a modo de aparato exegético que justifique la elección de la materia ínfima en la Grandeza mexicana. La obra de Balbuena es extremadamente retórica y su estructura se acomoda a la de un discurso deliberativo, dividido en definitio, probatio, confutatio y peroratio, aunque al final descubrimos que la intención verdadera es la de hacer de la obra una oratio epideictica, nacional y personal ${ }^{12}$. La perfección de esta estructura es importante para Balbuena, pues en último término, es su propia valía intelectual la que defiende con su obra: “...que también cuando pequeño pasé por los principios de retórica y llegué a los umbrales de la poesía” (pp. 146-147).

Igualmente esta característica relaciona su obra con la alabanza de la poesía de Valdés que preludia las Rimas de Vicente

8 Mabel Moraña, "Barroco y conciencia criolla en Hispanoamérica", RCLL, 1988, núm. 28, 229-251.

9 José Pascual Buxó, "Bernardo de Balbuena: el arte como artificio", Homenaje a José Durand, Verbum, Madrid, 1994, pp. 189-215.

10 Georgina Sabat de Rivers, "El Barroco de la contraconquista: primicias de una conciencia criolla de Balbuena y Domínguez Camargo", en Relecturas del Barroco de Indias, pp. 59-96.

${ }^{11}$ En este artículo la autora interpreta que la expresión "luz del ocaso", con que Balbuena califica a México, es síntoma de las actitudes de crítica contra la metrópoli (ocaso) y de alabanza de México (luz), cuando no se trata, creo yo, sino de la traducción al vernáculo del usado Occidens -tis ('ocaso'), para referirse a América, con lo que el sintagma se podría parafrasear como 'esplendor de América', del que se sigue una interpretación muy varia de la que ella obtiene.

12 Para la terminología utilizada en el análisis retórico, véase HeINRICH LausBERG, Manual de retórica literaria, trad. José Pérez Riesco, Gredos, Madrid, 1983. 
Espinel o con el prólogo de Lope a la edición de sus Rimas de 1609. La apología de Balbuena tiene el sentido último de defensa de su propia obra y de manifiesto literario. Todavía en este último sentido podemos traer a colación similitudes con el Ejemplar poético de Juan de la Cueva, defensa poética manierista (y personal) como la de Balbuena, o los manifiestos conceptista y culterano de Jáuregui y Carrillo de Sotomayor. El Compendio proclama la suficiencia del autor como autoridad y significa una voz de protesta en defensa de la perfección retórica del código compositivo de su Grandeza. A su vez, frente a la asepsia de poéticas que reducen su campo de aplicación al de la exquisitez erudita, la obra de Balbuena tiene la pasión del discurso epidíctico transformado en autodefensa.

Para dar un apropiado contexto retórico al Compendio hemos de indicar que la acusación contra la Grandeza de que Balbuena quiere defenderse es de índole eminentemente inventiva y elocutiva. El decoro de la materia no se guarda en ella, dicen sus críticos, porque se adopta un estilo elevado o sublime para una materia ínfima o baja. Con esta reprobación se desprestigia al autor, como se desprestigiará a Góngora en la polémica culterana, pues no se atiene al principio básico de la composición literaria. En segundo lugar, la elección de la misma materia es objeto de repulsa, pues no se atiene a la condición del escritor. El estado religioso en Balbuena le obliga a guardar un decoro a su persona y a la institución religiosa a la que pertenece. Con ello, el futuro obispo incorpora su libro al género polémico de las acusaciones contra fray Luis de León, porque había rebajado casi heréticamente un tema sagrado a un tratamiento vernáculo: contra Santa Teresa, porque su condición femenina no se avenía con el tema divino de su discurso; contra la poesía erótica, porque olvidaba el imperativo de la virtud en aras del deleite. El mismo Juan de la Cueva se defiende, en este sentido, de la crítica a su concepción teatral que Caravallo realizara en el Cisne de Apolo, y Lope hace otro tanto en su prólogo con respecto al asunto humilde de algunas de sus composiciones. Así las cosas, Balbuena ha de habérselas con una acusación de suma gravedad por lo que toca a la materia y al estilo de su obra, así como a su propia persona, acusado de impericia compositiva y de desconsideración del decoro de cosa y persona (decorus a persona reque). Y, hecho importante en esta polémica letrada, su impericia se une, irremediablemente, a su condición de indiano.

El carácter retórico externo de su obra, por otra parte, responde a un concepto particular de la retórica derivado de la ratio 
studiorum jesuita postridentina. Para esta orden, que comandaba la formación de la minoría letrada de América desde 1574, las artes humaniores serán las que saquen a la juventud ociosa de su incapacidad civil, llevándola "hacia el ejercicio de las letras, para el cual faltaban maestros y cuidado"13. La pericia formal, en este contexto, no capacita para la pertenencia al círculo de los sublimes, sino a la élite directiva; lejos de abrir la puerta de academias ociosas es el título del paso por el cursus honorum civil.

El Compendio responde a todas las acusaciones mediante una reflexión sobre la actividad poética y sobre el oficio de poeta, indagando en el contexto de producción y la finalidad de la primera y en la función del segundo. El exordio del Compendio constituye un repaso de autoridades laicas y religiosas defensoras de la poesía y los poetas. Éstas pertenecen al orden jurídico, filosófico y teológico y son representantes de una exaltación de lo civil, laico y organizador, de una parte; de la reflexión sobre la belleza o la inmortalidad, por otra; de la comunión del verbo humano y el verbo divino. Balbuena se preocupa en esta introducción por incorporar la poesía al cuerpo político de la ciudad, por hacer de ésta una construcción a la vez laica y divina y por insertarla dentro de una concepción armónica del universo. El contenido poético, para Balbuena, responde a "una admirable filosofía que enseña la razón del vivir, las costumbres y policía y el verdadero gobierno de las cosas" (p. 128), "poderosa a componer y corregir las costumbres y mover los afectos" (p. 129). La ratio jesuita que eleva a la juventud del ocio al gobierno revierte en Balbuena en una ordenación civil desde la cúspide, abarcando cosas y afectos en su mecanismo regulador y codificador. Se aprecia una cierta similitud de todo esto con la estrategia de creación de un estado en Bello. Como aquél, y probablemente por medio del ideario jesuita, Balbuena pone los cimientos de su reflexión sobre la base de una estructura político-administrativa (gobierno), una estructura reguladora y legal (componer y corregir) y una orientación propedéutica (enseña la razón). La estructura de su modelo intelectual es la de un edificio cívico, una estructura de jerarquía y de orden que afirma

13 Véase Juan Sánchez BaQuero, Fundación de la Compañia de Jesús en Nueva España, Nueva Patria, México, 1945. La crítica reciente está prestando cada vez más atención a este componente jesuita en la formación de la conciencia letrada. Así, Ángel Rama, op. cit., y MABel Moraña, "Barroco y la conciencia criolla en Hispanoamérica" y "Apologías y defensas: discursos de la marginalidad en el Barroco hispanoamericano". 
su mayoría de edad y su derecho a la autodeterminación. No se trata de independizarse de ningún poder central, sino de proclamar el derecho a incluirse en la estructura de poder que la misma metrópoli sustentaba, y ello se hace mediante la creación-definición de una auténtica maquinaria dotada de la belleza armónica que propagaban los tratados de Vitrubio, Palladio o Alberti.

En la transición a la narratio (p. 130) Balbuena insiste en la idea de que para la escritura de poesía se requieren "letras, experiencia y espíritu", así como "gran caudal de ingenio y estudio". Su preocupación por la ignorancia es la llave para el entendimiento del Compendio. Al inicio de éste, igual que en la peroratio, Balbuena insiste en que él está capacitado como poeta porque no le falta la ciencia que da autoridad a su oficio. Su intención será convencer al lector de que la poesía no es susceptible de crítica como género, sino los poetas, en quienes puede existir esta ignorancia en el nivel personal.

La siguiente parte del discurso comienza con una definición de lo que Balbuena entiende por poesía. Para él, ésta ha de ser "agudísimo estímulo a la virtud", entendida, como hemos indicado, dentro de un concepto público de la moral. Por lo que toca a la forma, Balbuena participa de una retorización de la poética, común a poéticas escritas en las mismas fechas. Así, la invención, disposición y elocución son "arroyos y manantiales de la poesía" (p. 131) y el estilo y sus componentes, definidos de acuerdo con términos retóricos, son también de "la jurisdicción del poeta". Este tema da pie al concepto de poesía como scientia scientiarum y al del poeta como eminente y caudaloso: "Que el que ha de ser perfeto y consumado poeta tiene obligación a ser general y consumado en todo y tener una universal noticia y eminencia y particular estudio y conocimiento de todas las cosas para tratar de todas y en ninguna ir a tiento" (pp. 131-132).

La narratio propiamente dicha se inicia con el desarrollo de la quaestio: la estima y dignidad de una ciencia se basa en su sujeto, la antigüedad de sus principios y la autoridad de sus profesores. La probatio de cada uno de estos apartados constituirá el centro del Compendio. Ha de notarse que la maniobra de Balbuena es sutil. El accesus auctorum señalaba que una obra de arte había de estudiarse según determinados pasos, entre los que figuraban la exposición del título, del autor, del contenido y de las partes de la misma. Balbuena recoge el mismo esquema para la defensa no de una obra, sino del género poético en su conjunto. Para el lector de la época el artificio debía resultar bien claro, puesto que sólo estaba 
acostumbrado a estudiar mediante el accessus obras consagradas como supremas por la tradición. De esta manera, la misma estructura expositiva presupone la elevación del tema, a la vez que aporta argumentos para probar, de nuevo, su sublimidad. Así también, el Compendio se puede leer metonímicamente como alabanza de la Grandeza de Balbuena, el esquema formal del accessus eleva al mismo Balbuena a la categoría de auctoritas.

El sujeto de la poesía es indeterminado, pues "discurre por todas las demás ciencias y facultades". La indeterminación de la materia permite que quepa en ella cualquier contenido, entre otros el de su Grandeza. Para Balbuena, la poesía es fundamentalmente exegética, en el sentido en que interpreta el ordo saeculorum divino; la construcción del universo representa un edificio armonioso y musical del que el poeta es interpres elogioso. La imagen pinta el ordo criaturarum en su canto y alabanza del Creador como un orden descendente de creación desde Dios a las criaturas y un orden ascendente de elogio en sentido inverso. El orden entero de la creación deriva de Dios y puede tener cabida en el poema.

Para Balbuena la filiación divina de la poesía representa una piedra de toque en la defensa de la misma. La poesía, dice, es antigua como el mundo, y prueba de ello son las "poesías y cantares" de los pueblos antiguos, ya sean las de "estos nuevos mundos occidentales", ya las que cuentan "los antiguos romanos de nuestra España".

El capítulo de las autoridades poéticas se remonta a Adán e Iubal y desciende por Moisés, David, Salomón y Job hasta los "príncipes humanos". Una vez que la poesía ha sido suficientemente autorizada por las Sagradas Escrituras, Balbuena desciende a la nómina de los poetas clásicos y contemporáneos. El elogio de los primeros se realiza en general mediante su relación con algún mecenas, general o emperador, destacando entre todos los géneros elogiados el de la épica-historia fundacional: Virgilio (Eneida), Petrarca (África) o Vida (Jerusalem). La nómina de los autores hispanolatinos, que sirve de transición al tratamiento de los contemporáneos, resalta el aspecto épico en Lucano, el filosófico en Séneca, el de represión de la moral en Marcial o el histórico en Silio Itálico, dando idea del concepto de poesía de Balbuena, que ha de conjugar el dulce et utile horaciano, atendiendo especialmente a "despertar la virtud". Con la nómina de autores "modernos" vuelven a resaltarse los mismos elementos que ya hemos visto para la de los clásicos. En especial se señala la relación poesía-poder, pues entre los nombres apuntados destacan los de personajes de la nobleza que no han pasado a englobar las listas canónicas de la 
historia literaria ${ }^{14}$. Más que una visión interesada de esta historia, me gusta ver en ella el concepto mismo de la poesía. La virtud y el gusto por las letras pertenecen a una clase rectora y poderosa que, entre sus cualidades, ha de contar con la del refinamiento y el gusto artístico. No estamos ante un concepto universalizante de lo poético, sino ante una visión elitista. La clase aristocrática es la clase gobernante a la que pueden acceder letrados por méritos especiales de valía artística, talento literario o conocimiento artístico. La primera reclasificación de las ciencias (El arte de trobar, de Villena) y la inclusión del poeta-historiador en el marco cortesano, fenómenos ambos pertenecientes al siglo xv, se ha convertido en la época de Balbuena y en América (bajo el auspicio de la enseñanza jesuita) en una inclusión del letrado en el organigrama de la ciudad como pieza fundamental en el engranaje político-administrativo de la misma. Esta posición elitista se diferencia de la de otros tratadistas, sin embargo, en el grado de compromiso con el poder político y en el contexto de ejercicio de la actividad poética. Prueba de esta visión elitista es la apostilla al nombre de Ercilla, que lo cataloga de "más célebre y conocido en el mundo por la excelencia de su poesía que por la notoria y antigua nobleza de su casa y linaje", que presupone como habitual el destacar en el oficio poético por la pertenencia a una casa ilustre. La nómina de los autores de "nuestros mundos occidentales" vuelve a resaltar esta especial relación de lo poético con el poder, a la que se une el tinte bélico que otorga la comparación de los imperios de las casas de Montesclaros, Monterrey y Lemos con las figuras de Augusto y Julio César. Sirve, por otra parte, para incorporar a la poesía americana a la tradición poética, dotándola de una mayoría intelectual.

Esta sección se cierra con una clasificación de géneros por orden de importancia, expresada de modo quiasmático: la épica y heroica ocupan la cima, seguidas de la lírica o mélica; igual ocurre con la poesía trágica, seguida por la cómica. Por lo que a esta última toca, y en oposición al tratamiento que la retórica solía darle, resalta la recuperación de su contenido, útil "para el gobierno y costumbres y policía pública” (p. 144). La tragedia, catártica y purificadora en el nivel personal, desmerece en esta catalogación a expensas de la comedia, que es elogiada en virtud de su contenido cívico.

\footnotetext{
${ }^{14}$ Cf., por su carácter de tópico, con la lista de Lope de Vega en el prólogo a sus Rimas (ed. cit.) o en su Arcadia.
} 
El siguiente apartado del Compendio lo constituye la confutatio de argumentos contra la poesía. La idea central es que, según la autoridad de fray Luis de León, el oficio de buen poeta está en hacer "obras graves, enteras, sentenciosas y llenas de moralidad y filosofía", y si hay poetas que no han hecho así no puede utilizarse para desacreditar el oficio poético sino como demérito de aquéllos.

La peroratio, finalmente, insiste en la idea de que la "falta poética" no está en el sujeto ni en la ciencia, sino en los "profesores, que eligen ocasiones y sujetos humildes". En esta parte del discurso pasa de lo general a lo particular, de la definición de lo poético a la alabanza de la propia poesía de Balbuena, abandonando el tono neutro de la aserción deliberativa por el marcadamente partidista de la autodefensa. Volviendo al esquema de la narratio del Compendio, el autor defiende su propia poesía de acuerdo con el sujeto, que es heroico: la grandeza de una ciudad ilustre y de su "heroico y santo Prelado"; de acuerdo con el tratamiento: virtuoso en su finalidad; y de acuerdo con su disposición, que no ofende ni la grandeza del tema ni el hábito del poeta. Por último, la figura de Balbuena es capacitada para el oficio poético por su conocimiento de la retórica y su adscripción al grupo de la res publica litterarum, aquí trasunto del grupo de poder efectivo. El dístico ovidiano catapulta a la fama la obra y la persona de Balbuena, que, como Homero y Virgilio, ha escrito una obra que pervivirá aunque el imperio en que se escribió sucumba ${ }^{15}$.

La reivindicación poética de Balbuena se asienta sobre el terreno teórico-práctico de la mayoría de edad intelectual americana. La polémica sobre el indio y sobre su capacidad intelecual se había trasladado metonímicamente y de modo peligroso a los habitantes de América de origen español. En este sentido, la polémica indigenista de mediados del siglo xvi se traslada, en la ideología del poder, a una polémica sobre la capacidad de gobierno y la capacidad de los españoles americanos. Tiene que ver no tanto con el peligro del desarrollo de una conciencia independentista cuanto con los resabios de una actitud paternalista tras la que laten intereses económicos y personales. Balbuena no pretende encontrar aquello que diferencia lo americano de lo peninsular, su intento es incluir lo americano dentro de la tradición ${ }^{16}$. Hemos, además, de representarnos de

15 Para el tema de la fama en el concepto poético de Balbuena, véase J. PASCUAL Buxó, art. cit.

${ }^{16}$ Hay que citar a Eugenio Salazar de Alarcón y su Epistola al insigne Fernando de Herrera (en Bartolomé José Gallardo, Ensayo de una biblioteca española de libros raros y curiosos, eds. M. R. Zarco del Valle y J. Sancho Rayón, Rivadeneyra, Madrid, 
modo claro los modelos culturales sobre los que se cimienta la actividad intelectual de la época: estos son los de la traditio e imitatio. En España se había experimentado desde el siglo XvI una reacción a las críticas italianas que rebajaban la valía intelectual del pueblo ibérico. Así, es frecuente leer en las obras españolas que, si la retórica se basa en el ser social del hombre, hay una retórica anterior a la reflexión artística griega y romana tal y como la practican los pueblos hispanos prerromanos. Del mismo modo, si la poesía es tan antigua como la humanidad y está sancionada por el uso bíblico, los teóricos españoles se preocupan por señalar fuentes ibéricas peninsulares pre y posromanas que dan testimonio de lo mismo. Balbuena, quien se preocupa por dotar de valía intelectual y de mayoría de edad a la reflexión americana, señala el ejemplo de los pueblos indígenas (p. 135), quienes, ayunos de letras, no carecían de poesía y de historia. De la misma manera, al ejemplo de poetas o mecenas españoles contemporáneos de Balbuena, se ofrece el ejemplo de los americanos, siguiendo el simple modelo de la confutatio mediante la presentación de ejemplos similares. No se trata, como parece a primera vista, de oponerlos, de presentar lo americano frente a lo peninsular, sino de incluir lo americano dentro de la tradición bíblica, clásica, italiana y española. Esto es, de proclamar su carácter de ciudad letrada y su capacidad, en un plano ideológico abstracto, para el gobierno. En este mismo sentido se han de entender los elogios a la ciudad de México en la Grandeza, realizados, entre otros recursos, mediante su comparación con las ciudades ilustres europeas. No se trata, repito, de un esquema opositivo, sino de uno de inclusión por imitación y participación de características comunes. No importa tanto la realidad material de los objetos de comparación cuanto su entidad de símbolos que se identifican en el esquema ideal.

1863-1889, t. 4, pp. 354-362), quien señala que América se incluye en esta nómina letrada porque de España y Toscana (vv. 118-123) llegan las producciones intelectuales y poéticas. Sin duda escrita con posterioridad a la llegada de los jesuitas y a la fundación de las primeras universidades, el elogio de Herrera se convierte en elogio de lo americano por extensión metonímica, basándose en la capacidad intelectual del receptor (wv. 61-64). El texto entero se erige en defensa del español-americano, que, para mostrarse autosuficiente, ha de recibir "la ayuda de subjetos muy peritos, / flores de los ingenios más floridos / y prendas de varones eruditos". La epístola de Salazar, en la que la autoridad proviene a través de la línea Dios-Virrey-Herrera-poeta americano, muestra en este afán de suficiencia intelectual más de una similitud con la obra de Balbuena. Nótese, además, que en Salazar este prestigio intelectual tiene una clara vinculación manierista. 
La reivindicación americana en Balbuena puede encontrar paralelos con el desarrollo de las conciencias peninsulares. Ercilla, quien merece elogios extraordinarios a Balbuena por el tema de su Araucana, es catalogado dentro de la nómina poética española, mientras don Lorenzo de los Ríos y Ugarte, incluido entre los americanos, es elogiado por la "heroica y feliz vena" con que "va describiendo las maravillosas hazañas del Cid" (p. 142). La misma creación de modelos míticos en Balbuena pasa por la exaltación de La Araucana y la elección de Bernardo del Carpio como héroe nacional-personal. El reconocimiento americano como algo diferente de lo peninsular está presente en la obra de Balbuena, aunque sólo de la misma manera como se identificaban frente a los castellanos el grupo de Mal Lara en Sevilla o el grupo zaragozano de los Argensola; o de la misma manera que otros tratadistas poéticos, al señalar el origen de las lenguas, no dudaban en distinguir la catalana, la valenciana, la vasca, la portuguesa y la castellana como lenguas-culturas diferentes. No me parece que los términos "nación" y "reinos occidentales", que aparecen en la Grandeza o el Compendio, hayan de ser entendidos en un sentido prenacionalista, sino como sintomáticos de una conciencia regionalista que, sin embargo, no cuestiona la validez del poder central. No se me escapa, sin embargo, que la lejanía de la metrópoli y las especiales condiciones de estos "reinos occidentales" permitan distinguir este fenómeno de la conciencia americana del de la simple conciencia aragonesa o sevillana, en especial cuando nos situamos en una perspectiva histórica amplia que contempla la evolución política e ideológica de cada una de estas regiones. La ideología del interés en la obra de Balbuena, que tan bien ha sabido explicar Buxó, permite sospechar que su obra elogia y acepta un modelo de imperialismo y de gobierno del que él mismo quiere formar parte.

El Compendio apologético da pie para pensar en una suficiencia estética tras la que se esconde un sentimiento de grupo. Sin duda que este carácter puede estar en el origen de posteriores reflexiones nacionalistas o criollistas, ausentes aquí de un nombre que les dé ser. El Compendio sí muestra, sin embargo, una clara relación con el poder. A través de diferentes niveles y estructuras los reinos occidentales, la ciudad letrada y, sobre todo, la persona de Balbuena encuentran legitimación como entidades de ordenamiento.

El primer nivel habla de la relación entre ciudad divina y ciudad humana. Los reinos occidentales son, así, autorizados por su inclusión en un universo cristiano y su exclusión del barbarismo indígena. La poesía, en términos abstractos, es legitimada fren- 
te a los ataques de indecorosa (decoro religioso) y Balbuena encuentra una justificación para la adecuación de su persona al tema poético de la Grandeza. La línea de legitimación desciende de Dios a la ciudad cristiana, de ésta a la persona-entidad del obispo (en su persona individual y en el estamento religioso que representa) y de éste a la persona de Balbuena en su función sacerdotal.

El segundo nivel trata de la ciudad humana como ciudad letrada. Balbuena pone los fundamentos de la autosuficiencia mexicana en su condición letrada, mediante la inclusión de los reinos occidentales (México en particular) en el esquema del saber. Frente a Dios como eje superior de la pirámide jerárquica se erige la clasicidad o el pasado reciente ya elevado a condición de autoridad. La búsqueda de un pasado remoto que justifique la condición retórica latente americana se encuentra en los cantos de los pueblos indígenas, parangonados a los de los pueblos hispanos prerromanos; la idea enhebradora en este nivel no es la palabra revelada sino la palabra civilizadora. De la condición verbal de los pueblos indígenas pasamos a la de los príncipes regentes en su condición de mecenas y a la suficiencia letrada de la corte de poetas y literatos, cultivadores de la palabra poética. Los dos niveles, que han de leerse de modo yuxtapuesto y complementario, nunca paratáctico e independiente, acaban, no obstante, en la proclamación individual de Balbuena como individuo letrado.

El verbum divino y el verbum humano producen una división estructuradora de los dos niveles. La tiara y el cetro -el órgano de poder político, la academia letrada y la iglesia jerárquica- se acaban reuniendo en la base de la pirámide en la persona de Balbuena, quien por su oficio religioso y su conocimiento letrado queda aupado a la condición de sabio perfecto. En este proceso de justificación personal, Balbuena ha legitimado cada una de las instancias superiores en las que se incluye poniendo los fundamentos de un edificio de autoridad de poder (humano y divino) encerrado en los límites de la ciudad.

El interés, finalmente, se constituye en móvil político y personal. Este concepto, de nuevo de raigambre humanista, sirve para explicar el desarrollo de la justificación mercantilista de las actitudes económicas de los gobernantes en América. La doctrina permitía que sobre él se cimentara la política imperialista española, en especial, su actuación en América, así como las políticas particulares ciudadanas, ya sea las de las ciudades italianas o, en específico, de las flamencas. En el plano personal e individual, el interés y el beneficio se acomodan, otra vez, a la figura de Balbuena, ávi- 
do de ganancia y reconocimiento (interés económico e intelectual). Con ello se cierra un círculo que el mismo autor expresaba en la primera octava de su Grandeza, al señalar aquello que será objeto de descriptio en su obra: situación de lugar, suntuosidad de bienes materiales (calles, edificios, etc.), importancia de la gente que la puebla, etcétera.

\section{Consideraciones FINALES}

Fuera de interpretaciones forzadas de la obra de Balbuena que no encuentran un refuerzo textual e histórico, este análisis del Compendio apologético gira en torno a la idea de poesía civil que está en la base de su defensa poética.

La comparación con otras obras de alabanza poética resulta importante por cuanto señala las mismas fuentes para muchas de ellas. La redefinición de las ciencias, según se entendía el concepto en el siglo $\mathrm{xv}$, tiene como origen la nueva posición que los letrados ocupan en las cortes, así como la ascensión de la nobleza y la aristocracia a la categoría letrada. Esta redefinición se realiza teniendo como base las ciencias de la palabra, en especial mediante una reconsideración de la retórica y la gramática. El concepto de hombre que sale de esta nueva especulación filosófica ahonda en las raíces verbales de la condición humana, aunando los conceptos de consecución de la virtud, sabiduría y verdad a través del estudio de la palabra humana y de la divina.

Este concepto de la sabiduría y del estudio, de la elocuencia diríamos en términos humanistas, tiene una dimensión teórica y una práctica, que, en el plano filosófico, se representa mediante la escisión de ciencias especulativas y ciencias prácticas. Por vez primera desde la reflexión clásica, y superando el concepto agustiniano del hombre como habitante de la civitas Dei, el contexto social, cívico y político en el que el hombre se incluye va a tener repercusiones decisivas para la definición del ser humano. El marco de la corte, el de la ciudad y el del estado elevan al hombre poco a poco de su condición de ser individual a la de zoon politikon. Como la reflexión humanista se encargará de señalar, la sociedad rectora se ordenará de acuerdo con la capacidad elocutiva del hombre, dando así una especial importancia al estudio de las ciencias de la palabra.

La sociedad de nuevo cuño formada de esta manera no desechaba lo religioso como aspecto constitutivo del hombre. Sin embar- 
go, frente al mundo teocentrista que se acababa, el nuevo mundo de relaciones hombre-Dios pedía un sistema filosófico que diera cuenta de las nuevas expectativas. El neoplatonismo, desde mediados del siglo xv, se ofreció como el sistema que conjugaba la idealidad de la nueva visión humana con la relación divina que la religión como código cultural pedía. Este sistema estructuraba jerárquicamente el orden de la creación y del universo, señalando una serie de grados descendentes y ascendentes de participación en el ordenamiento del mundo. El sistema no sólo era válido para explicar la relación de las criaturas con Dios, sino que permitía englobar en él modelos de relación social de nueva planta, en especial en la Italia de las ciudades estado. Por si esto fuera poco, los modelos de participación, recuerdo, imitación y copia del modelo filosófico eran válidos también para la reflexión estética.

El poeta, entendido en el sentido amplio de la palabra en la concepción de la época, se ve así transformado de cortesano palaciego en demiurgo. Esta noción incorporaba ideas tales como la de la participación de lo poético en lo virtuoso y en lo verdadero. Con el paso de la reflexión poética a la reflexión sobre el poeta se incorporaba todo el edificio estético al nuevo orden ciudadano, haciendo del letrado-sabio-virtuoso una figura ideal para regir la sociedad. La idea podía encontrar una acogida instantánea en Italia, donde incluso la figura de algunos príncipes rectores como Cosimo de Medici aunaba en sí la figura de príncipe y la de poeta. El letrado, así, se ve reflexionando sobre asuntos morales, más que políticos tal y como hoy los entendemos, que tienen que ver con las costumbres o con la reflexión sobre el modo de organizar una sociedad. Su papel de consejero encuentra una faceta práctica que explica la preocupación de Erasmo o Vives por escribir tratados sobre la condición de la esposa cristiana o sobre medidas para acabar con la mendicidad, igual que en Sebastián Fox Morcillo su preocupación sobre la educación lo lleva a pedir una separación efectiva entre Iglesia y Estado.

Siendo común el contexto cultural en que surgen la obra de Balbuena y otras poéticas que utilizan el mismo bagaje de autoridades que ésta, las miras diferentes que cada una ofrece, sin embargo, permiten señalar matices. Autores como Mesa del Olmeda adoptan la posición del pseudo-retiro universitario y conciben la poesía desde la posición de la moral individual ${ }^{17}$. El perfecciona-

17 Mesa de Olmeda es autor de una poética llamada Digresionario poético de todos los metros, así españoles como italianos, escrita entre 1585 y 1595, que se con- 
miento personal y el conocimiento de uno mismo son las causas finales de la actividad poética. El edificio político que ofrecen las fuentes que utilizan se ha reducido a la res publica litterarum. Balbuena, sin embargo, retomando el interés de los primeros humanistas italianos del siglo xv, entiende la poesía como portadora de virtud, aunque su concepto de la moral como individuo en sociedad se amplía de lo individual a lo público.

Aquellos autores ofrecen una reflexión estetizante, situada en los límites del aula o de la comunidad de letrados, donde la ignorancia señala la frontera del mundo exquisito de la sabiduría. Balbuena ofrece una consideración de la poesía en la que la ciudad, como contexto político, sirve de telón de fondo a una doble ordenación del poder: de una parte la que deriva de la ecuación príncipe-poeta; de otra, la que se obtiene de la de prelado-sacerdote. La ignorancia, también abominada por Balbuena en los mismos términos que en autores como Olmeda, señala el ascenso de los españoles americanos y de México a la categoría de suficientes. Esta suficiencia cultural, cuando menos una dirección legítima de lectura del discurso de Balbuena, significa, en términos más prácticos, la suficiencia para ejercer el poder, ya sea civil o religioso.

No encontramos en Europa por las mismas fechas una motivación similar a la de Balbuena. En Italia, tras las obras de Patrizi y Robertello, la preocupación estética cerrará su horizonte de aplicación al de la obra literaria. En Francia la misma reflexión política se centrará en La méthode historique de Bodin, que pone los cimientos a una filosofía de la historia, elaboración doctrinal ajena a la realidad de una nación en desarrollo. En España, la obra

serva manuscrita e inédita en el vol. 135 de varios, Fernán Núñez Collection, Bancroft Library, University of California, Berkeley (MS UCB 143) y de la que hemos preparado un estudio (en prensa). De la comparación de los dos textos, el de Olmeda y el de Balbuena, resulta la asombrosa coincidencia en las fuentes utilizadas. Ambas obras, sin embargo, presuponen ideas de poesía diametralmente opuestas. Mientras el edificio teórico revierte con Olmeda en la defensa de una poesía elitista, que pertenece al círculo de los letrados, para Balbuena el mismo grupo de autoridades refuerza una idea civil y comprometida de la poesía. Los dos tratados, además, coinciden en su estructura. En el Digresionario, la última parte es una traducción de Olmeda de la Batracomiomaquia pseudohomérica, a modo de breve epilio alejandrino cuyo carácter de nuga la convierte en pequeña exquisitez lírica. En Balbuena, el Compendio precede a la Grandeza, poema épico mayor de tinte exaltado y fundacional. Entre ambos autores, pues, hay la distancia que lleva de la épica homérica o virgiliana al rococó del epilio alejandrino. 
de Saavedra Fajardo acabará desterrando a los poetas de los límites de la ciudad como incapaces de todo gobierno.

Balbuena, sin embargo, establece una ecuación entre poesía y civilidad que hay que ver en parte, como fruto de la realidad americana. El interés personal (no el altruismo lascasiano ni la conciencia del pueblo del Inca Garcilaso) se canaliza a través de un discurso reverente con el poder metropolitano (semejante a Salazar), preocupado por señalar la capacidad intelectual propia y de los reinos occidentales para ordenar, regir y dominar unas tierras en ejercicio a la par virtuoso y lucrativo.

\section{Poesía y épica. Momentos de la definición de un sujeto colonial}

La tendencia de la crítica literaria es la de adelantar en el tiempo el nacimiento de la conciencia criolla, en un afán justificado por responder a necesidades de identidad actuales ${ }^{18}$. Si cada época busca a sus modelos culturales en el pasado, ya sea para adherirse u oponerse a ellos, la crítica ha ido buscando fuentes en el pasado que justifiquen la llegada a una conciencia diferencial e independentista en Hispanoamérica. El siglo xvIII, en especial desde la historiografía literaria, parece contar más y más con el favor de la crítica para buscar una conciencia americana a la que calificar de precriolla ${ }^{19}$. De modo paralelo, el último tercio del siglo XVII (a partir de la reflexión contemporánea sobre el ser barroco americano) se ha incluido en el campo de mira de la crítica que paulatinamente avanza en retroceso con el intento de incorporar autores y obras al proceso de creación del sujeto americano-colonial ${ }^{20}$. El peligro de esta reflexión no es desconocido para nadie, y aun alguno que otro estudio ya publicado ha pecado de excesivo apriorismo bien intencionado, que, lejos de integrar épocas, autores y conceptos en una historia literaria e ideológica coherente, fuerza la reflexión desde el anacronismo y la impropiedad.

El proceso de creación del sujeto americano pasa por diferentes fases de agrupamiento, oposición e identidad que no pueden

18 Véase el prólogo y el epílogo de JuAn Durán Luzio, Bartolomé de las Casas ante la conquista de América. Las voces del historiador, Editorial de la Universidad Nacional, San José de Costa Rica, 1992.

19 Cf. M. Moraña, "Formación del pensamiento crítico-literario en Hispanoamérica: época colonial".

20 Cf. John Beverly, "Nuevas vacilaciones sobre el barroco", RCLL, 1988, núm. 28, 215-227. 
dejar de verse, como proceso vivo que sigue siendo, desde la óptica presente. Por lo que toca a una de sus modalidades, la de la conciencia criolla, la identidad reivindicativa y escisionista coincide con la lucha armada con la metrópoli en un momento en que el sujeto es consciente de su condición de sujeción involuntaria. Las fases por las que se llega a este momento son tres, a mi entender:

La primera coincide con la época de la definición de la nueva realidad americana (geográfica, material y humana) posterior a la conquista. Las Casas y el Inca Garcilaso suponen dos voces de tonos diferentes unidas por su afán de definición. La defensa del indio en ambos casos presupone el acceso previo de los dos autores a la categoría autorizada de letrado para desde allí enunciar su definitio. La defensa de la condición humana del indio y la exposición del pasado y grandeza culturales suponen un fenómeno similar al que nos transmiten las literaturas vernáculas con el cultivo de las chansons de geste y la historiografía medieval de tonos épicos.

Son dos los géneros literarios que nos reflejan el tránsito de una fase a otra entre el siglo Xvi y el xvir: la épica y las poéticas. El pasado remoto precolombino se sustituye por el pasado reciente de la conquista o la épica-elogio contemporánea de la América virreinal. El marco regional y el grupo humano sito en dicho contexto constituyen los puntos de referencia obligatorios para cualquier reflexión posterior sobre la esencia del sujeto americano. Tierra y pueblo, pues, son constituyentes necesarios de un órgano nacional todavía no definido. Asimismo, frente a la identificación que la metrópoli produce entre los españoles americanos y los indios en determinadas circunstancias, la élite superior de los mismos españoles americanos se esfuerza por marcar un límite claro de escisión entre ellos y la población indígena, aun a pesar de la caracterización lírica idealista del indio, que lo retrata en la mayoría de las ocasiones ubicado en el pasado y con notas de irrealidad inverosímiles.

Con la noción de gobierno y orden entramos en la definición del tercer elemento imprescindible para la constitución estatal. Este orden, que acabará siendo nacional, tiene, sin embargo, en este momento de paso entre un siglo y otro un carácter marcadamente ciudadano. El fenómeno se corresponde con el desarrollo del roman en el siglo XII en Francia, así como con la reflexión teórico-crítica de las arts poétiques de la misma época. Para América puede citarse un número no elevado pero sí proporcionalmente grande de textos teóricos que definen el carácter civil de la poesía (Salazar, "Clorinda", Balbuena). En todos ellos se percibe una 
nueva conciencia difícil de definir, que de modo recurrente habla por vez primera de "nuestras tierras occidentales". Se percibe, también por vez primera, una conciencia de grupo que nunca se define de acuerdo con la individualidad sino con la colectividad. Por otra parte, este nuevo grupo sube conscientemente a la condición de igualdad con respecto a la metrópoli, todavía sin propósito alguno de oposición, pero sí con el deseo de llamar la atención sobre su capacidad participativa. Este proceso provoca en la literatura determinados conceptos hasta cierto punto ambiguos si se los analiza desde nuestra situación presente. No se trata de una voluntad de oposición a lo español peninsular desde una identidad definida y diferente, sino de la primera conciencia de la existencia de un grupo americano que se incluye dentro de la máquina política e imperialista para afirmarse como sujeto colectivo. La primera definición de este sujeto múltiple (los reinos occidentales) se logra, pues, dentro de la incorporación a la identidad española. La imitación y la consecución de una autoridad letrada son los modos de obtención-afirmación de tal identidad, que ya se había dejado vislumbrar en Las Casas o en el Inca Garcilaso ${ }^{21}$.

A medida que el siglo Xvir avanza se observa por vez primera en Camargo y Sor Juana un movimiento de agitación de la identidad que sólo concluirá en la obra de la historiografía literaria ilustrada, donde aparecen las notas de diferencia y exclusividad, todavía en germen en el último tercio del siglo xviI. Así, sólo en este momento podrá empezarse a definir lo americano sin necesidad de acudir a lo español para encontrar un respaldo identificador y de autoridad.

La creación del sujeto colonial en estas tres fases reviste las características de una asimilación imitativa y de una consecución de autoridad desde el sometimiento (sujeto-sujeción). Balbuena supone un segundo momento en la definición del sujeto colonial. En este proceso que acaba marcando el paso de sujeto pasivo a sujeto enunciativo en el siglo xix, Balbuena no representa conciencia precriolla alguna en un sentido anacrónico. $\mathrm{Su}$ voz es simplemente la de una afirmación individual (interés, fama) dentro de una identificación colectiva (grupo, reinos occidentales), que necesita para su simple expresión alzarse a la con-

${ }^{21}$ Véase mi discusión sobre el carácter humanista de Las Casas en "El prólogo a la Historia de las Indias: Bartolomé de las Casas humanista", RevIb, 170/171 (1995). 
dición de autoridad mediante la imitación y copia de unos modelos de ejercicio poético y de poder. Así, el sujeto va de la definición -que lo eleva a categoría jurídica y a la condición de ente existente- a la identidad dentro del grupo, por medio de la afirmación de su autoridad. De aquí, sin embargo, a la conciencia de la diferenciación y del derecho de autodeterminación queda más de un siglo y medio.

Antonio Cortijo Ocaña University of California, Berkeley 